\section{intrinsic Positive Endexpiratory}

Pressure

Helga Peter ${ }^{1}$ und Thomas Penzel ${ }^{2}$

${ }^{1}$ Marburg, Deutschland

${ }^{2}$ Interdisziplinäres Schlafmedizinisches Zentrum, Charité Universitätsmedizin Berlin, Berlin, Deutschland

\section{Synonyme}

iPEEP

\section{Definition}

Intrinsischer positiver endexspiratorischer Druck. Siehe $\triangleright$,iPEEP“. 